\title{
Parents' Daily Household Activities on Child Litter Awareness: An Action Research Case
}

\author{
Tsebo Kgoto Matsekoleng ${ }^{1^{*}}$ \\ ${ }^{1}$ University of South Africa, SOUTH AFRICA
}

Received 29 May 2020 - Accepted 9 September 2020

\begin{abstract}
This study emanates from behaviorism theory and cooperative paradigm, which evaluates the effects of parents' daily household activities regarding littering on children through participatory action research approach. Litter is a socio-cultural environmental issue that degrade environment. Additionally, pre-packed foods and other disposable items contribute to littering as people discard covering items on the ground after consumption. Three children from three families were case studied at home. Semi-structured interviews, pictures, questionnaire and participant observation were used to collect data. Coding process was used to analyse data. The results of the study show that parents' daily household activities has minimal effect on children's awareness of littering. The researcher recommends further studies to explore the impact of parents' daily household activities on children's understanding of environmental issues.
\end{abstract}

Keywords: behaviourism theory, environmental education, household activities, littering, progressive environmental action research activities

\section{INTRODUCTION}

This article explores the effects of parents' daily household activities on child litter awareness through the application of participatory action research and behaviourism theory from three families. For a child to learn about environmental problems should be engaged in the learning process through imitations, demonstrations and communication as it was indicated during the interviews. Collado, Evans and Sorrel (2017, p. 34) aver that children tend to observe the behaviour of significant others, and learn such behaviour by imitation. As such, a child adopts family norms on certain issues (Abeliotis, Goussia-Rizou, Sdrali, \& Vassiloudis, 2010). Thus, most decisions about consumption and other private economic affairs are made in families, children are born and raised here, and they are socialised to become (more or less) responsible citizens in their family (Grønhøj, \& Thøgersen, 2012, p. 292).

With that in mind, a number of environmental issues such as littering, that are incipient in our modern societies are largely driven by our modern lifestyle in our families (Matsekoleng, 2017). For instance, people buy electronic appliances, pre-packed foods such as takeaways and other disposable items. Once these prepacked goods are consumed and electronic appliances are damaged people discard them on the bare ground, which results in littering (Matsekoleng, 2017). As well, people litter the environment influenced by intrinsic and extrinsic motivations. Intrinsic motivation refers to motivation associated with activities that are their own reward and extrinsic motivation refers to motivation created by external factors such as rewards and punishment (Woolfolk, 2010, p. 377). For example, most of the time adults at home clean their house/yard as observed in the study perhaps these influence children to litter home environment haphazardly. The effects of behavioural mediation regarding parents' attitudes or methodologies is an area that warrant careful research.

Scholars in the past conducted studies that have examined different aspects of households settings. Likewise, studies conducted in South Africa by Kamara (2006) and Strydom (2018) explored household recycling behaviour, and Ramukhwatho, du Plessis and Oelofse (2018) assessed household food wastage. In Germany, Matthies, Selge and Klöckner (2012) examined recycling at home while Miliute-Plepiene and Plepys (2015) reviewed waste management systems at home in

(c) 2020 by the authors; licensee Modestum. This article is an open access article distributed under the terms and conditions of the Creative Commons Attribution License (http://creativecommons.org/licenses/by/4.0/).

mabu@live.com (*Correspondence) 


\section{Contribution to the literature}

- The study filled a gap in the literature by inspiring environmental education scholars to embark on participatory action research to awake household activities to raise child litter awareness, so that littering is reduced in the environment.

- Behaviourism theory strengthened parent and child relationship by encouraging collaborative household activities to mitigate littering behaviour at home.

- Progressive environmental action research activities has proven to be a better approach to conscientise children towards litter in their homes.

Sweden. Additionally, Collado et al (2017) in Spain evaluated parents' environmental behaviours and in Italy Riverso, Amato and La Barbera (2017) investigated household food waste habit. Andersen (2016) deliberated children as intergenerational environmental change agents in their family homes in Australia. Mech and Ojah (2016) in India assessed the awareness, practices and factors associated with hand washing amongst mothers. In Denmark, Grønhøj and Thøgersen conducted studies in 2012 and 2017 that examined proenvironmental behaviour on personal attitudes and family norms. Lastly, Kirana (2018) explored the role of mothers on how they educate their children to keep a clean environment in Indonesia.

Abovementioned studies used variety of research methods and their research approaches differs. From these studies, it is evident that there is paucity of literature on littering at home. Also, little has been done in using participatory action research approach within households to examine parents' daily household activities on child litter awareness. With this study, the researcher attempt to fill that gap by sharing experiences gained through progressive environmental action research (PEAR) activities regarding littering. Synergy of participatory action research and PEAR in the study is that participatory action research promotes hands-on environmental activities in environmental education. While PEAR activities stems from this approach since it forms part of the participatory methods and situated learning process (Matsekoleng \& Mapotse, 2020). Literature reports that participation is a central feature of participatory action research (Le Grange, 2009). In light of this, PEAR and participatory action research advocate participative activities that could lead action competence. PEAR activities refers to environmental campaign activities conducted with children in their homes continuously. The researcher use the term children or learner(s) interchangeable in the study referring to participant(s).

In light of the aforementioned literature, this study anticipates answering this research question: What are the effects of parents' daily household activities on child litter awareness?

\section{RESEARCH PROBLEM}

\section{Aim of the Study}

The aim of the study is to explore the effects of parents' daily household activities on child litter awareness.

\section{Problem Statement}

A growing concern of environmental issues in South Africa saw an increasing number of environmental campaigns to raise household members' awareness on environmental issues. Such campaigns includes "Good Green Deeds" with the intention of conscientising society on environmental issues. The President of South Africa Cyril Matamela Ramaphosa launched this campaign on 8 March 2019 to shape up people littering behaviour concerning the environment among other issues. It was reported that culture of mishandling wastes continues today, encouraged by lax governmental environmental supervision and excessive concern for profits, investment and private gain (Southall, 2018). Thus, lifestyle changes encourage an increased demand for discarded goods and packaging (Statistics South Africa, 2018, p. 30). In view of that, Loubser, Swanepoel and Chacko (2001) states that, a clean and healthy environment is, however, dependent on the level of environmental literacy of a nation. It is therefore important to focus on parents' daily household activities to raise child litter awareness.

\section{Pre Intervention}

PEAR activities in the study is informed by the presence of littered items at children's homes. PEAR activities included starting up a vegetable garden, planting seeds, cleaning their yards, making compost, planting flowers and crocheting. On daily basis, case studied families used items that are wrapped up by plastics and some of the covers end up on the bare ground leading to littering. It is reported that if the amount of food wasted is not reduced, there will be a need to increase food production globally on already constrained land and water resources (Ramukhwatho et al., 2018). The increase in food production will mean increased packaging, which will lead to littering if residents dispose items improperly. In their study, 
Ramukhwatho et al. (2018) found that households wasted an average of $6 \mathrm{~kg}$ of food per week.

Various items such as buckets and other items are left disorganised from case studied families. This pointed that families were lacking environmental awareness, which contributed towards littering (Matsekoleng, 2017). In some instances, their litterbins were not emptied regularly which led to overflowing which also contributed to littering. Furthermore, the researcher observed that environmental activities such as gardening were not conducted at home. Most of the activities at home are also carried by adults which taking away some of the responsibilities that children should perform, which could raise their awareness of littering. Having said that, this paved a way for implementation of PEAR activities at home to conscientise children on litter issues.

\section{Theoretical Framework Underpinning the Study}

In 1913, John Broadus Watson coined the term behaviourism theory. In his theory, he argues that it was not scientific for psychologists to deal with unobservable phenomena such as conscious or thought, and that science had to deal with observable behaviours (Bacanli, 2016). Since the birth of the behaviourism theory, there was a revolution of the theory. Behaviourists' scholars such as Burrhus Frederick Skinner, Ivan Petrich Pavlov, Edward Chace Tolman, Edward Lee Thorndike, Edwin Ray Guthrie, Albert Bandura and Julian Rotter expanded the theory.

In the latest publication of Schultz and Schultz (2007), reported that Bandura and Rotter explored methodological behaviourist while Watson and Skinner studied radical behaviourist. It is argued that radical behaviourists believe that psychology should study just the observable behaviours and environmental processes, while methodological behaviourists think that cognitive processes can also be studied, but methods of behaviourist approach should be used (Schultz \& Schultz, 2007). These kinds of behaviourist approach fit the intention of this study. Researcher scrutinise parents' daily household activities (methodological behaviourist) to ascertain the effect that might have on children litter awareness. The ineffectiveness of households activities are strengthen by PEAR activities (radical behaviourist) to raise children awareness towards littering with the intention of changing their behaviour of littering. Therefore, it can be argued that methodological and radical behaviourist are intertwined in this study.

In a real life situation for children to learn methods and actions should take place to activate stimulus and response of the problem and as such, learning becomes meaningful through every day learning activities. As was the case in this study, researcher engaged children at home through PEAR activities in a collaborative manner to conscientise them towards littering. The children who were involved in the activities used their senses, muscles, hearts and brains, and learned something in the process (Torkos, 2017). This was done to change their behaviour of littering.

For that reason, behaviourism theory suits the exploration of participatory action research and household activities because most of its activities are practical, which could develop action competence for children. A behaviourist approach to the implementation of participatory action research and household activities could provide children with the opportunity to mould their littering behaviour. For instance, implementation of PEAR activities (radical behaviourist) with children at home envisaged raising their awareness of littering in a collaborative inquiry. Equally, it was anticipated that when engaging children in a behaviourist theory, an intervention becomes much more meaningful and empowering if it is not merely instructive: if children contribute on finding solutions to challenges and take action, they have a vested interest in the outcome (Mapotse \& Mashiloane, 2017).

Littering is a social environmental issue. Hence, this study applied a collaborative/cooperative paradigm to engage children to find ways of conscientising children of littering at home. A collaborative paradigm puts emphasis on active learning through participation, as children are involved in decision-making throughout the process. This led to four participatory action research cyclic processes encompassing planning, action, observation and reflection. A researcher worked with the children throughout this research journey, engaging in PEAR activities to conscientise them about littering. Accordingly, an assumption was made that engaging children in a behaviourism theory would develop an understanding of littering in their milieu and develop action competence, which led to finding ways of complementing household activities. In the following section, the researcher discuss methodology of the study.

\section{METHODOLOGY}

\section{Research Design}

This study is a qualitative research, which explores parents' daily household activities on child litter awareness from three families. In qualitative research, researcher collect artefacts, stories, phrases, words, images and all kinds of symbols that will assist in creating a deeper understanding of a phenomenon ( $\mathrm{du}$ Plooy-Cilliers, 2014, p. 290) which supplement descriptive data collection methods. These symbols characterise types of data collected when using participatory, emancipatory, technical and practical action research. Participatory action research design was deemed fit for this study to assess the effectiveness of parents' daily household activities on child litter 
awareness from three families working with one child in each family.

\section{Selection of Participants}

The researcher shed light on the purpose of the study with the children in their classes. Once details regarding participation were discussed, a number of learners came forward to be part of the study. Accordingly, the researcher used convenience sampling to select two learners per class out of seven classes that volunteered to be part of the study. Due to the nature of action research, the researcher sampled 14 learners in order to have manageable population from seven classes. Learners are convenient as they can be available to the researcher during school days (Pascoe, 2014). Learners were selected from classes regardless of their age among other things. Selected learners were aged between 12 and 14 . After consultation with parents, the researcher used three learners from three households/families out of 14 . Three families were case studied based on their availability and willingness. Likewise, other families were not residing in the area where this study was conducted.

\section{Data Collection Instruments and Process of Data Collection}

Data was collected from the children's parents through a semi-structured interview. Thirteen parents were interviewed out of 14 owing to unreachability of one parent but three families were case studied based on their availability as stated above.

Interviews were conducted at home with parents using a digital recorder and cell phone. However, some questions from the interviews were poorly answered. This was owing to language barrier and even after it was translated to IsiZulu and Sesotho versions. In addition, pictures, questionnaires and participant observation were used to collect data from the children. In support, Skinner (1974) avers that behaviour can be recorded in different forms using variety of research instruments as alluded above. The intention of using pictures, questionnaires and participant observation was to consolidate the data collected from the interviews with parents. In addition, questionnaires and interview questions were piloted with the learners; but these learners were not part of participants in the actual study. A pilot study is used to determine whether the participants understood all the questions in the questionnaire correctly (Koonin, 2014). Similarly, University of South Africa ethics committee approved usage of the instruments.

The researcher-visited three families twice a month for a period of nine months and these families included one boy and two girls. These children were engaged in PEAR activities at home, and their ages range between 12 and 14 years. The findings of the study are generalised to the participating families. As the researcher used small sample and could not reach other families due to unavailability and relocations.

\section{Data Analysis}

The researcher transcribed the raw data from the parents' response through a digital recorder. By transcribing data, the researcher gets to understand data better (Bezuidenhout, \& Cronje, 2014). This affords the researcher to immensely engage with data. The coding process was used to analyse interview responses by assigning meaningful codes next to interview responses. Subsequently, data collected from the interviews was coded to determine emerging ideas. Later, the researcher grouped emerged ideas together into themes, in order to engage with the findings extensively.

Computer programs such as ATLAS.ti are available to analyse qualitative data (Bezuidenhout \& Cronje, 2014; McMillan \& Schumacher, 2010). Despite that, the researcher used Microsoft office 2016 suite. The researcher used a word processor and a spreadsheet program to capture the transcribed interview responses. The use of tables aimed to analyse data collected from research instruments. Three children from three families were observed throughout intervention programmes that we conducted and observed data was transcribed to have meaningful meaning. Additionally, total score percentages were also used to analyse data from the qualitative questionnaire. This was done to show distribution of data among children on the researched problem and the success of intervention after implementation of the programme.

\section{Families Case Studied}

The researcher named the three families after colours comprising of Gold Family, Orange Family and Green Family to conceal their identity. Each family had one participant; one boy and two girls, all were engaged in the PEAR activities at home. The three families participated in this case study based on their availability and at their convenient time. Other families could not take part owing to their personal reasons such as "I am working from Monday to Friday and I come back late at home so I won't have time to participate since on weekends I do household tasks". This was also evident during data collection stage, where the researcher struggled to find some of the parents to conduct the interviews with. Consequently, the researcher managed to interview 13 parents out of 14 . From these 13 families only three families and their children worked with the researcher were case studied at home for a number of reasons as pointed earlier.

\section{The Green Family}

This family has three members at home comprising of grandmother, child (participant), uncle and one tenant 
staying in a backroom. They are staying in a spacious three bedroomed house, a kitchen, dining room and lounge, and a toilet outside. The grandmother is involved in a community garden. The co-researcher was 14 years old. They placed big litterbin outside the house. There are also peach trees and flowers around the yard. Behind backrooms, there are various items such as steel bars, window frames, buckets, chairs, beer casket, bricks and other items left disorganised. The grandmother and uncle in the family carry out most of the activities including cooking and cleaning.

\section{Orange family}

The child (participant) stays with the mother and three siblings. They stay in four-roomed house with outside toilet. The child was 12 years old. The mother works at a hospital as a cleaner. The eldest son and mother carry out most of the activities at home. There is absence of flowers and plants in the yard. There are two immobile scrapped cars parked inside the yard. There is visibility of unwanted items lying around the yard although they have three litterbins outside the house. Two tenant are renting shacks, which perhaps place pressure on usage of litterbins among other things.

\section{Gold family}

This family has eight members including grandmother, mother, uncle, two aunts and three children (participant included). The child was 14 years old. The grandmother, uncle and kids share the main house (two bedrooms, kitchen and lounge). The aunts and mother of the child occupy backrooms. The child rarely engage in household chores on daily basis as the adults carry them out. They have a lawn garden and it is well maintained, but with no trees within the yard. The yard is largely paved from the back to the front. Plastic wrappers can be noticed on the ground. Research results are discussed below.

\section{RESEARCH RESULTS}

\section{Analysis of the Interviews}

This section discusses data collected from the interviews with the parents. The researcher interviewed 13 parents out of 14 due to unavailability of one parent, which is equivalent to 85 per cent female and 15 per cent male. The researcher discusses data collected from all the parents that were interviewed owing to their context and similarity in the responses. Although, after the interview three children from three families were case studied as alluded above. This section discuss household activities, environmental awareness, responsibilities, rearing and availability of litterbins.

\section{Household Activities}

Household activities refer to daily general activities that are carried out at home daily by household members. Activities that promote cleanliness, were the most general activities stated by the parents. Their responses seem to downplay central features of participatory action research of involving children in household activities frequently. Some of the responses comprise:

"I am working so after work at home I clean, cook and check children's schoolbooks if they wrote their homework and if they took a bath before they go to bed" parent said 4 .

".....I start cleaning around the yard in the morning then when done then move into the house...." parent commented ${ }^{13}$.

Seven out of 13 parents stated that their daily activities influence children not to litter and intergenerational learning process seemed to occur. Some of the verbatim extracted from the interviews read as follows:

A parent 8 indicated that "Yea I am not going to allow my child to be a litterer. To litter everything and to drop everything because I have the dustbin in the house. When you see garbage on the ground then you have to put it inside the dustbin. If the dustbin is full inside the house, there is another big dustbin outside drop it in there".

In accord, another parent ${ }^{1}$ highlighted that:

$$
\begin{aligned}
& \text { "...it teaches her especially when she sees me } \\
& \text { performing such duties on days when she is tired. She } \\
& \text { realises that even when she is visiting she needs to wash } \\
& \text { dishes before she goes to bed, clean the toilet and sweep } \\
& \text { the yard in the morning. I am teaching her even though } \\
& \text { I am not telling her exactly in words, she learns from } \\
& \text { me as I have learned from my upbringing". }
\end{aligned}
$$

\section{Environmental awareness}

Environmental awareness refers to behaviour of an individual within their immediate environment. Responses of parents indicate that they are concerned about their environment, which point that they have environmental awareness. Their reaction towards unwanted material on the ground indicate that they have positive attitude towards the environment. However, their anti-littering and environmental awareness is not shown on their children's behaviour as revealed by the questionnaire.

Responses from parents show that they have positive attitude towards the environment. As they pick up unwanted items on the ground. Verbatim from the interviews confirm that, 
"We pick them up and throw in the dustbin" parent 6 commented.

Another parent ${ }^{2}$ said,

"I always pick them up litter and place it separately in refuse bags for people who are collecting for recycling".

Parents have positive attitude towards the environment according to their responses. They highlighted that they have not littered in a long time, they do not litter the environment and do not remember littering. Extract from the interviews:

Parent ${ }^{10}$ commented, "I can't recall since I know it's unhealthy. I have young kids who look up to us as adults and littering in front of them is very wrong. So I normally put the wrappers in the bag and dispose them when I get home. It is wrong to litter even when you are out on the streets because young kids pick up bad behavioural patterns much faster. I regard every child as my own and don't want them to learn such bad things from me".

Parents' responses show that their daily activities towards the environment are positive. Quote from the interviews reads as follows:

"Yes, I always observe my yard and when I see something untidy then I attend to it promptly. Like I said it about the trees, they are totally obscuring light from the kitchen so bad that it should always be lit" parent ${ }^{9}$ said.

\section{Responsibilities}

Responsibilities refer to duty(ies) an individual performs at home. Everyone at home is expected to perform household tasks. As indicated in the interviews, all the parents stated that their children do clean at home. Participation mentioned above is considered as key in participatory action research, it is important for parents to involve children in their daily activities for betterment of their upbringing. However, children clean occasionally.

A parent ${ }^{5}$ stated that "Yes, she does clean but not always because I am always at home. She cleans on weekends when she doesn't have much of school work".

A parent ${ }^{12}$ further stated that:

"Yes my child does clean, if maybe the mother is doing night shift or maybe day shift and she comes home very late around 6 or 7 'oclock at night. When he comes back from school, is normally me, him, and the other young ones. So he cleans a kitchen and dining room. The sitting room is not normally that dirty but the kitchen and dining room becomes very dirty because people walk in and out as you see we have a small business outside there. He washes dishes as well".

\section{Rearing}

Rearing refers to a learning process that parents reinforce in their households to teach children about environment and environmental issues. Learning is a process that includes experiences and other processes (Mashiloane \& Mapotse, 2018a). From such rearing can strengthen intergenerational learning. Parents from the interviews stated general daily activities and most activities such as cleaning the house are related to general cleanliness of the house. Most parents mentioned supervision, demonstration and communication as the methods that they use to ensure children are environmentally literate. Supervision, demonstration and communication play a crucial role in participatory action research for changes to occur. Verbatim extracted from the interviews:

"I show her where she didn't clean properly. I demonstrate and we do it both then she learns from that" parent ${ }^{3}$ said.

In support of the statement, parent ${ }^{7}$ indicated that

"I sit him down because sometime when I get back from night shift I find the house disorganised because you know children like freedom. I wake them up and monitor them as they put the house back in order".

These views indicate that the families' ecopolitics are (increasingly) domestic and managed, occasionally intensified and monitored by the mother (Payne, 2010).

\section{Availability of litterbins}

Availability of litterbins in this context refer to adequate dustbins in the households to dispose unwanted items. The availability of litterbins around the yard were stated. Majority of parents indicated that their households had two litterbins inside and outside the house. Extracted verbatim from the interview read as follows:

"We have a small bin in the house and the bigger one outside. When the small one is full we put garbage in the refuse bag and empty it into the bigger one" parent ${ }^{11}$ said.

Further, the availability of litterbins at home was highlighted by another parent ${ }^{6}$ who said,

"I have two dustbins, the smaller one in the house and the bigger one outside".

In summation of the above, parents' daily household activities stated are limited to house chores and parents perform most of the activities. A program of methodological behaviourism became plausible only when progress began to be made in the scientific observation of behaviour (Skinner, 1974). In this case, there is absence of environmental activities at home, 
which such activities could improve methodological behaviourism of children. Lack of environmental activities hold back the objective of participatory action research approach. Further, parents seemed to have positive attitude towards the environment, however, this seemed not to filter down to their children as revealed by the questionnaire.

\section{Analysis of the questionnaire}

The researcher gave children two sets of the questionnaires at the beginning and end of the study aiming to compare the outcomes after implementation of interventions programme at home. Fourteen children completed first set of the questionnaire and second set the number of children that completed the questionnaire previously declined to nine due to withdrawals.

\section{Daily household activities}

The pre-analysis of the questionnaire shows activity/activities performed by children were below average (50.0 per cent). Therefore, the researcher could not draw conclusion. The post analysis 66.7 per cent of children indicated that they clean house and wash dishes. It is a significant shift from the pre-analysis and proves that PEAR activities at home had an effect on the children. As expected in participatory action research project, a change is an anticipated outcome.

\section{Awareness}

A number of children on pre-analysis indicated that they do not litter their home environment, which contradicted their yards' appearance as littered items were observed on the ground and pictures captured support this. It is therefore true as 35.7 per cent of children indicated littering home environment. After intervention programme few items were found on the ground and perhaps foreign objects landed in their yards and this fact was mentioned from the interviews: "....as you see how this season is, foreign items are flown/blown in to the yard and I tell them to never leave such unattended....." parent $^{2}$ said.

\section{Responsibility}

On the pre-analysis it was not clear for people who should keep home environment clean at all times as the responses were below average (50.0 per cent). The post analysis showed 66.7 per cent of children declaring children and parents should keep home environment clean. In contradiction, Kirana's (2018) study revealed that environmental issues are the responsibility of parents. Pre and post analysis showed the beauty of participatory action research as it encourages children to take part in keeping their homes clean.

\section{Analysis of the pictures}

The researcher captured two sets of pictures to compare the effectiveness of the intervention as shown on Table 1. The pictures meant to address trustworthiness issue. Pictures have supplemented other research instruments discussed in the study. Pictures revealed that both families' have littered items misplaced on the ground, which proved that littering does occur at home. Experiences and environment constitute a human's personality (Bacanli, 2016). Since the introduction of PEAR activities of crocheting, gardening and cleaning up at home, their yards have improved. In participatory action research, change is eminent. Even though, few littered items are visible on the ground.

\section{Participant observation}

This section presents PEAR activities conducted with children at home (see Figure 1) through spiral cycles to raise their awareness of littering. The PEAR activities were conducted with children in their homes. Several cyclic activities covered aspects such as exploration of soil and wastes. PEAR activities using participatory action research spiral cycles encompassed starting up a vegetable garden, planting seeds, cleaning their yards, making compost, planting flowers and crocheting, as this calls on children to use their hands, hearts and minds (Mashiloane \& Mapotse, 2018b). These active

Table 1. PEAR activities

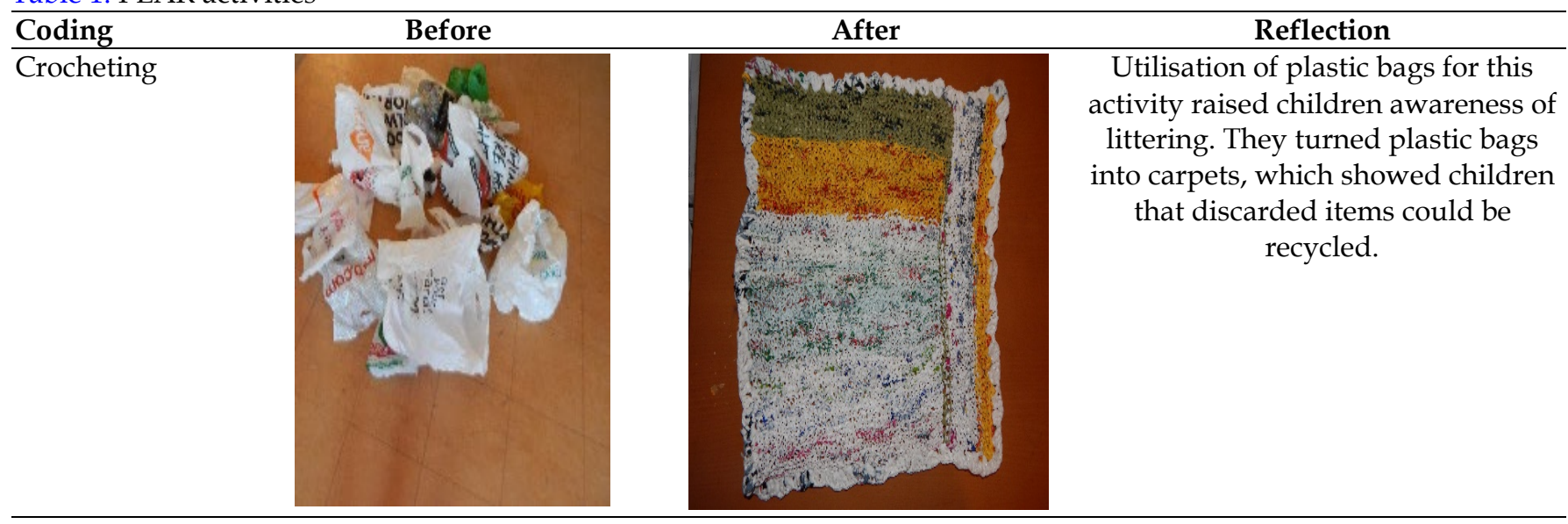


Table 1 (Continued). PEAR activities

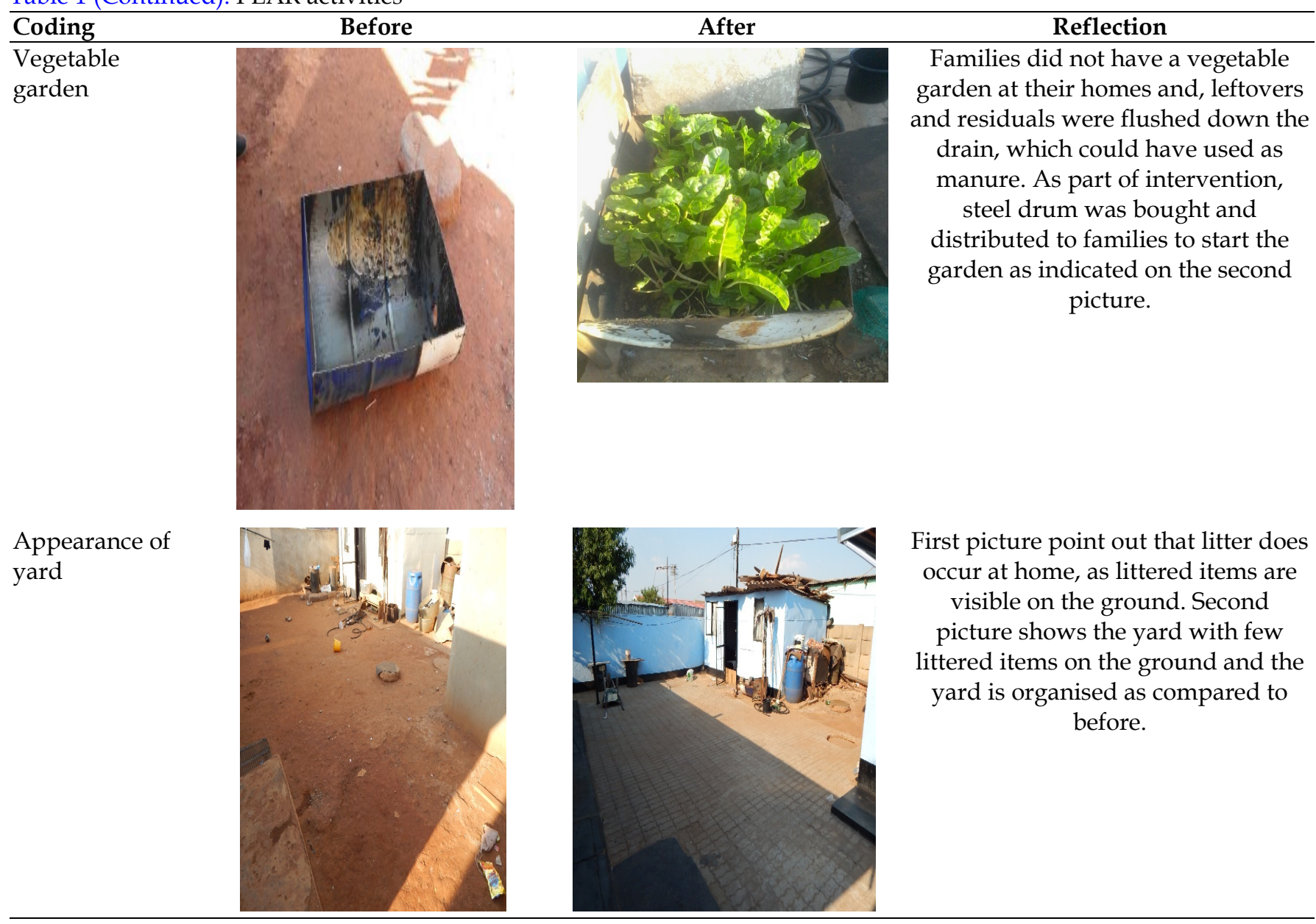

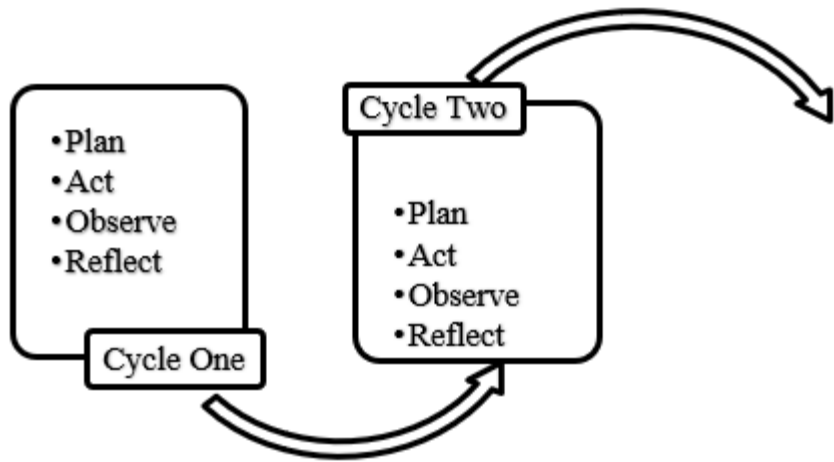

Figure 1. Spiral cycles with children

activities promote environmental education and participatory action research at home. With these activities, knowledge about the environment becomes personal knowledge rather than school knowledge and children learn to care for their environment (Gough, 2016). Intrinsically, activities in the form of concrete examples are good ways for children to protect the environment (Kirana, 2018, p. 6).

In the first cycle presented in Figure 1, children got an empty half drum and filled it with soil, which had to be cultivated and watered first, to plant the seeds for the preparation of the vegetable garden. The children had to further plant flowers for Arbour day, which required the
Table 2. Summarised both children activities per cycle

\begin{tabular}{ll}
\hline Activities per Cycle & Children Activities \\
\hline Spiral Cycle 1 & $\begin{array}{l}\text { Soil exploration and } \\
\text { environmental day celebration }\end{array}$ \\
Spiral Cycle 2 & $\begin{array}{l}\text { Reuse and recycling of waste } \\
\text { materials }\end{array}$ \\
\hline
\end{tabular}

soil to be prepared again. Now the families have vegetable gardens and flowers decorating their homes since we intervened, except the Green family that did not plant flowers. In cycle two, displayed in Figure 1, children used plastic that can be classified as waste material to make (crochet) mats and hats from, that way it was turned into useful material. They also made compost from decomposable waste materials, to fertilise the soil for their garden.

The researcher summarises children activities per spiral cycle in Table 2, which was developed from Figure 1.

Children were part of decision-making and taking action as a way of raising awareness of littering in a collaborative engagement including planning, acting, observing and reflecting. Socially critical approaches to environmental education advance the idea of authentic participation in which all participants are involved in all dimensions of the research (conceptualisation, planning 
and execution) (Le Grange, 2009). With that in mind, PEAR activities aim to demonstrate that environmental literacy is accessible to everyone and, that environmental problems are everyone's business (Gough, 2016). PEAR activities successfully raised children awareness of littering and eased their littering behaviour. Radical behaviourism took different lines to give children an opportunity to do self-observation or self-knowledge (Skinner, 1974). Ensuing section discusses research findings.

\section{DISCUSSIONS}

This article explored the effects of parents' daily household activities on child litter awareness and framed around behaviourism theory. The results are derived from three case studied families.

Skinner (1974, p. 211) highlights that the major problems facing the world today can be solved only if we improve our understanding of human behaviour. In this case, it is important to understand the effects of parents' daily household activities on children's awareness of littering. The literature suggests that in this era and age communication should be a focal point to understand and deliver the message about environmental issues to children (Kirana, 2018). Collado et al. (2017, p. 35) alludes that the degree in which parental pro-environmentalism is transmitted to children appears to rely on family communication modes. As mentioned in this study, parents stated supervision, demonstration and verbal communication as methods to make children environmentally literate. However, all these methods mostly focused on the cleanliness of the house and yard. Environmental activities such as planting flowers and other activities were not stated as a way of ensuring that children are environmentally literate to change their behaviour towards the environment.

For many children, the attention of an adult can be a rewarding consequence, that is, social reinforcement (Wasik, Senn, Welch, \& Cooper, 1969). Mech and Ojah (2016) study found that there was awareness among the mothers regarding the importance of hand washing in the prevention of diseases. This finding is in accord with the finding of this study as was stated from the interviews; "I tell her how to dust off, wash dishes...." This was the affirmation that mothers love cleanliness and PEAR activities had a role to play at home, as children are now frequently engaged in home activities. Radical behaviourism restores some kind of balance (Skinner, 1974) within household activities. It was the indication that their behaviour to some extent has changed. As Adam and Barratt-Pugh (2020) argues that when children see characters and situations familiar to them, a sense of affirmation can occur.

Kirana (2018) found role of mothers, social context, and child's capacity as some factors that shaped human behaviour in keeping a clean environment. Grønhøj and Thøgersen (2017) point that parents could nourish their children's motivation to act on environmental issues. These include letting children to observe that they engage in pro-environmental household activities; possessing self-determined motivation towards 'doing things for the environment; providing for a communication environment conveying choice and agency for the young person to act and providing structure and setting expectations with regard to the preferred mode of pro-environmental action. These aspects promote participatory action research at home. However, literature suggests that young people do not copy their parents' behaviour mechanically, but develop motivation towards behaviour observed on an everyday basis. This is because social norms influence their behaviour (Scott, Oates, \& Young, 2015). This study observed that if children are constantly reminded about their duties and engage in those duties it will raise their awareness concerning environmental issues. For instance, children started vegetable garden by filling the drum with soil, applied manure to fertilise the soil, watered the garden, planted seeds and continued to maintain the garden. Behaviour can be changed through reinforcement and studies have shown that reinforcement is more efficient than punishment (Bacanli, 2016). This influenced children to be considerate of the environment and shaped their behaviour on environmental issues including littering.

Andersen (2016) found that parents from most families took control of the programme, which was implemented at home. In this study, as it was revealed from the questionnaire and interviews that children clean "sometimes" which shows that parents took control of the household activities. Hence, Andersen (2016) concluded that the Protocol (refers to programme that was carried out) had limited effectiveness in enabling the children to change the behaviour of their parents and siblings. Conversely, since the implementation of PEAR activities in this study, children took control of the activities and the activities were carried out successfully. Kirana (2018, p. 5) states that children or other family members can maintain environmental cleanliness because their parents provide examples directly to them. Although in this study, parents' environmental methods are limited to household activities i.e. cleaning and cooking. Hands-on and self-exploration activities like gardening were not stated.

The indoor ecopolitics of the families focussed primarily on the issues of cleanliness (Payne, 2010). Parents stated from the interviews that general daily activities and most activities such as cleaning the house are related to general cleanliness of the house. Questionnaire revealed cleaning the house and washing dishes as children's daily activities. Grønhøj and Thøgersen (2012) reported that attitude plays a role on 
performing such activities. These activities promote environmental education within the house and to the children littering awareness only to a certain extent. These activities have a minimal impact though parents indicated that their daily activities influence children not to litter the environment. Nevertheless, their daily activities does not influence children to stop littering. "I normally pick them up and put them in the dustbin then later I would find them outside the yard. Still it doesn't make any difference, then a day later after picking them I find more plastics" parent ${ }^{1}$ said. It is discerning that children are often the ones not cooperating despite awareness created at schools (Strydom, 2018). Further, parents may be fully committed on certain environmental issues, but if they do not communicate (for instance, through praise) their attitudes to their children, the transmission of those attitudes and behaviours to their children might be difficult (Collado et al., 2017, p. 34). From this observation, the results of this study showed that parents' daily household activities have minimal impact on children, which path a way for conclusion.

\section{CONCLUSION}

This article explored the effects of parents' daily household activities on child litter awareness through the application of behaviourism theory. Children were engaged in PEAR activities through the application of participatory action research cycles of observation, planning, action and reflection to raise their awareness of littering. Participatory action research cycles made environmental activities to be fun and at the same time, learning has occurred. All the activities were aimed to raise children awareness of littering within their households and improve their littering behaviour. Thirteen interviewed parents revealed the activities that are carried out daily at home but are limited to household chores. On the other hand, children completed a questionnaire that indicated activities that they perform at home promoting household chores. It was observed that littering does occur at home, and pictures taken support this finding.

From the above observation, parents always perform most of the household activities such as cleaning the house and yard, while children do household activities occasionally as argued above. As such, lack of consistency influences children not to clean at home frequently. This implies that children in the morning do not make up their bed because that forms part of cleaning. General activities as stated above are limited to household chores and as a result, PEAR activities were implemented and carried out successfully. As it was observed, environmental activities are not carried out, as they should be. Household daily activities do not address any environmental activity except sweeping but littered items were found on the ground. Pictures taken before intervention support the observation as presented above. Although parents perform these activities, to a certain extent promote environmental activities such as sweeping.

Furthermore, parents' positive attitude towards littering is not evident on their children's attitude towards the environment. Even though parents mentioned supervision, demonstration and communication to mould children awareness of littering. Additionally, on average families had two rubbish bins but one can spot littered items in the yard. As a result, these instruments interviews, questionnaire, observation and pictures point that environmental activities are not conducted at home and conclusion can be drawn that parents' daily household activities have minimal impact on children's litter awareness.

This study will help parents at home and relevant stakeholders to engage children in PEAR activities that conscientise child concerning littering. As such, the activities conducted with children paved a way for Africans and other scholars to embark on environmental education and participatory action research activities at home to explore parents' daily household activities on children's awareness on environmental problems. The use of participatory action research in a research anticipates change in the research context. Participatory action research is about the "art of what is possible", given a myriad of constraints (Le Grange, 2009, p. 12). This article contributes in advancing indigenous education within household education, which focus on significant issues relevant to international audience regarding changing in parent pedagogical reform in (and relating to environmental education) household education.

\section{REFERENCES}

Abeliotis, K., Goussia-Rizou, M., Sdrali, D., \& Vassiloudis, I. (2010). How parents report their environmental attitudes: a case study from Greece. Environment Development and Sustainability, 12(3), 329-339. https://doi.org/10.1007/s10668-0099197-0

Adam, H., \& Barratt-Pugh C. (2020). The challenge of monoculturalism: What books are educators sharing with children and what messages do they send? The Australian Educational Researcher, 1-22. https:/ / doi.org/10.1007/s13384-019-00375-7

Andersen, P. J. (2016). Children as intergenerational environmental change agents: Using a negotiated protocol to foster environmentally responsible behaviour in the family home (Unpublished DEd thesis). University of Wollongong, New South Wales. https:/ / doi.org/10.1080/13504622.2017.1392487

Bacanli, H. (2016). Behaviourist approach. In C. Akdeniz, H. Bacanli, E. Baysen, M. Çakmak, N. Çeliköz, N. Doğruer, \& H. I. Yalin (Eds.), Learning and Teaching: Theories, Approaches and Models (pp. 19-30). Ankara, Turkiye: Cozum. 
Bezuidenhout, R., \& Cronje, F. (2014). Qualitative data analysis. In F. Plooy-Cilliers, C. Davis \& R. Bezuidenhout (Eds.), Research matters ( $7^{\text {th }}$ ed., pp. 228-251). Cape Town: Juta and Company Ltd.

Collado, S., Evans, G. W., \& Sorrel, M. A. (2017). The role of parents and best friends in children's proenvironmentalism: Differences according to age and gender. Journal of Environmental Psychology, 54, 27-37. https:/ / doi.org/10.1016/j.jenvp.2017.09.007

du Plooy-Cilliers, F. (2014). The research proposal. In F. Plooy-Cilliers, C. Davis \& R. Bezuidenhout (Eds.), Research matters (7th ed., pp. 282-293). Cape Town: Juta and Company Ltd.

Gough, N. (2016). Australian outdoor (and) environmental education research: senses of 'place' in two constituencies. Journal of Outdoor and Environmental Education, 19(2), 1-11. https:/ / doi.org/10.1007/BF03400990

Grønhøj, A., \& Thøgersen, J. (2012). Action speaks louder than words: The effect of personal attitudes and family norms on adolescents' pro-environmental behaviour. Journal of Economic Psychology, 33, 292302. https:/ / doi.org/10.1016/j.joep.2011.10.001

Grønhøj, A., \& Thøgersen, J. (2017). Why young people do things for the environment: The role of parenting for adolescents' motivation to engage in pro-environmental behaviour. Journal of Environmental Psychology, 54, 11-19. https:/ / doi.org/10.1016/j.jenvp.2017.09.005

Kamara, A. J. (2006). Household participation in domestic waste disposal and recycling in the Tshwane Metropolitan Area: An environmental education perspective (Unpublished MEd Dissertation). University of South Africa, Pretoria.

Kirana, C. (2018). Communication between mothers and children about environmental issues (a study about the role of mothers to educate their children on keeping a clean environment). In E3S Web of Conferences (Vol. 74, 08012). EDP Sciences. https:/ / doi.org/10.1051/e3sconf/20187408012

Koonin, M. (2014). Validity and reliability. In F. PlooyCilliers, C. Davis \& R. Beziudenhout (Eds.), Research matters (7th ed., pp. 252-261). Cape Town: Juta and Company Ltd.

Le Grange, L. (2009). Participation and participatory action research in environmental education processes: For what are people empowered? Australian Journal of Environmental Education, 25, 314. https:// doi.org/10.1017/S0814062600000367

Loubser, C. P., Swanepoel, C. H., \& Chacko, C. P. C. (2001). Concept formulation for environmental literacy. South African Journal of Education, 21(4), 317-323.

Mapotse, T. A., \& Mashiloane, T. K. (2017). Nurturing Learners' Awareness of Littering through
Environmental Campaigns: An Action Research Approach. Eurasia Journal of Mathematics, Science and Technology Education, 13(10), 6909-6921. https:/ / doi.org/10.12973/ ejmste/76658

Mashiloane, T. K., \& Mapotse, T. A. (2018a). Conscientise learners with littering in environmental education by using action research activities. In T. A., Mapotse (Ed.), Cross-disciplinary approaches to action research and action learning (pp. 256-270). Hershey PA: IGI Global.

Matsekoleng, T. K. (2017). Learners' environmental awareness, effects on home and school practices towards littering: An action research case. (Unpublished MEd Dissertation). University of South Africa, Pretoria.

Matsekoleng, T. K., \& Mapotse T. A. (2020). Improved attitudes towards littering through progressive action research activities in an Environmental Education context. Asia-Pacific Journal of Teacher Education. https:/ / doi.org/10.1080/1359866X.2020.1793906

Matsekoleng, T. K., \& Mapotse, T. A. (2018b). Mitigate littering through action research activities: an action oriented knowledge-based environmental study. Rethinking Teaching and learning in the 21st century.

Matthies, E., Selge, S., \& Klöckner, C. A. (2012). The role of parental behaviour for the development of behaviour specific environmental norms - The example of recycling and re-use behaviour. Journal of Environmental Psychology, 32, 277-284. https:// doi.org/10.1016/j.jenvp.2012.04.003

McMillan, J. H., \& Schumacher, S. (2010). Research in education - evidence-based inquiry (7th ed.). Boston: Pearson Education Inc.

Mech, K., \& Ojah, J. A. (2016). Study on the awareness and practices of hand washing amongst mothers of under-five children in the slums of Guwahati city. Journal of Evidence Based Medicine and Healthcare, 3(24), 1075-1078. https://doi.org/10.18410/ jebmh/2016/247

Miliute-Plepiene, J., \& Plepys, A. (2015). Does food sorting prevents and improves sorting of household waste? A case in Sweden. Journal of Cleaner Production, 101, 182-192. https://doi.org/ 10.1016/j.jclepro.2015.04.013

Pascoe, G. (2014). Sampling. In F. Plooy-Cilliers, C. Davis \& R. Bezuidenhout (Eds.), Research matters (7th ed., pp. 131-146). Cape Town: Juta and Company Ltd.

Payne, P. G. (2010). Moral spaces, the struggle for an intergenerational environmental ethics and the social ecology of families: an 'other' form of environmental education. Environmental Education Research, 16(2), 209-231. https://doi.org/10.1080/ 13504620903580545 
Ramukhwatho, F., du Plessis, R., \& Oelofse, S. (2018). Preliminary drivers associated with household food waste generation in South Africa. Applied Environmental Education and Communication, 17(3), 254-265.

https:/ / doi.org/10.1080/1533015X.2017.1398690

Riverso, R., Amato, M., \& La Barbera, F. (2017). The effect of food waste habit on future intention to reduce household food waste. Quality-Access to Success, 18, 369-375.

Schultz, D., \& Schultz, S. E. (2007). History of modern psychology. The Journal of Academic Social Science Studies, 6(8), 645-664.

Scott, A., Oates, C., \& Young, W. (2015). A conceptual framework of the adoption and practice of environmental actions in households. Sustainability, 7, 5793-5818. https:// doi.org/10.3390/su7055793

Skinner, B. F. (1974). About behaviorism. New York: Knopf.

Southall, R. (2018). Littering in South Africa is the expression of wider selfish - and costly - culture. Retrieved from https://theconversation.com/ littering-in-south-africa-is-the-expression-ofwider-selfish-and-costly-culture-96186

Statistics South Africa. (2018). Environment, in-depth analysis of the General Household Survey 20022016. GHS Series Report Volume IX.

Strydom W. F. (2018). The social dilemma of household recycling. Proceedings of Waste Conference 2018, Emperors Palace, Johannesburg, 15-19 October 2018.

Torkos, H. (2017). Social and psychological aspects of outdoor education. Agora Psycho-Pragmatica, 1(1), 215-223.

Wasik, B. H., Senn, K., Welch, R. H., \& Cooper, B. R. (1969). Behaviour modification with culturally deprived school children: two case studies. Journal of Applied Behavior Analysis, 2(3), 181-194. https:/ / doi.org/10.1901/jaba.1969.2-181

Watson, J. B. (1913). Psychology as the behaviourist views it. Psychological Review, 20, 158-177. https: / / doi.org/10.1037/h0074428

Woolfolk, A. (2010). Educational psychology (11 th Ed.). Boston: Pearson.

\section{http://www.ejmste.com}

